\title{
Arbeitsablauf zur Behandlung des Trockenen Auges, ein Versuch der Zuordnung von Diagnose zur Therapie
}

\author{
Johannes Nepp · Jutta Horwath-Winter · Christoph Mitsch · Ingrid Boldin · Dieter Franz Rabensteiner · \\ Andreas Wedrich
}

Eingegangen: 11. Februar 2016 / Angenommen: 29. März 2016 / Online publiziert: 9. Juni 2016

(C) The Author(s) 2016. This article is available at SpringerLink with Open Access

\begin{abstract}
Zusammenfassung
Hintergrund Das Trockene Auge ist eine sehr komplexe Erkrankung der Augenoberfläche. Zur Behandlung bieten sich eine Vielzahl von Tränenersatzmitteln mit unterschiedlichen Inhaltsstoffen an sowie diverse Methoden. Diese Arbeit entwickelt ein Schema zur Anwendung der in Österreich erhältlichen Produkte.

Material und Methode Aus der Literatur werden verschiedene diagnostische Verfahren, ätiologische/ pathogenetische Mechanismen sowie Beschreibungen der Schweregrade den therapeutischen Möglichkeiten für das Trockene Auge gegenübergestellt. Daraus entsteht eine Arbeitstabelle, welche als Grundlage zur erleichterten Behandlung dieser Erkrankung dienen soll.

Resultate Es werden 149 Tränenersatzmittel/Therapeutika für das Trockene Auge in der Arbeitstabelle erfasst, welche je nach Diagnose und dem Schweregrad zu den Therapiemöglichkeiten in 9 Untergruppen zugeordnet werden.

Schlussfolgerung Der Arbeitsablauf zur Behandlung dieser Erkrankung beinhaltet die Schritte von der Symptomatik, Diagnostik und Einordnung der subjektiven und objektiven Parameter bis zur optimierten Therapie mit den in Österreich erhältlichen Produkten.
\end{abstract}

\footnotetext{
Ass.Prof. Dr. J. Nepp ( $\bowtie) \cdot$ Dr. C. Mitsch

Universitätsaugenklinik, Medizinischen Universität Wien,

Währinger Gürtel 18-20, Wien, Österreich

E-Mail: johannes.nepp@meduniwien.ac.at

PD. Dr. J. Horwath-Winter · PD Dr. I. Boldin .

Dr. D. F. Rabensteiner · Univ.Prof. Dr. A. Wedrich

Universitätsaugenklinik, Medizinischen Universität Graz,

Graz, Österreich
}

Schlüsselwörter Trockenes Auge $\cdot$ Pathogenese $\cdot$ Diagnostik · Schweregrad · Tränenersatzmittel · Therapiemöglichkeiten · Arbeitstabelle

Workflow-chart for dry eye management from diagnosis to therapy

\section{Summary}

Background Dry eye is a complex disease of the ocular surface. Many artificial tear medications are available with different components and modes of application. This paper develops a schematic chart of the medications and application modes available in Austria.

Material and methods A comparative literature search of the causes, diagnostic procedures and severity of dry eye syndrome to create a workflow chart for facilitating dry eye management.

Results 149 artificial tear medications and application methods were entered in the workflow sheet, subdivided into 9 management groups according to diagnosis and severity level.

Conclusion This work process includes hints and steps based on patient complaints,classified into subjective and objective factors, to optimize management of dry eye

Keywords Dry eye $\cdot$ Pathogenesis · Diagnostics · Severity - Artificial tears - Therapeutic options - Workflowchart
Abkürzungen
BAC Benzalkoniumchlorid
$\mathrm{BH} \quad$ Bindehaut
BUT Break-up-time (Tränenfilmaufreißzeit)
CHDG Chlorhexidin-Digluconat
CMC Carboxymethylcellulose $=$ Carmellose
CsA Cyclosporin/Ciclosporin 
DEWS Dry Eye Workshop

DHA Docosahexaensäure

EDO Einmaldosisophtiole

EPA Eicosapentaensäure

GLA Gamma-Linolensäure

HA Hyaluronsäure, Hyaluronan, Hyaluronat, Hylan

HDMO Hydroxydimethyloxolan

HMG Hydroxymetholgluconat

HP GuarHydroxypropyl-Guar

HPMC Hydroxypropylmethylcellulose = Hypromellose, Methocel

kA Keine Angaben

MDO Multidosisophtiole

MGD Meibomian Gland Dysfunction

ÖOG Österreichische Ophthalmologische Gesellschaft

PEG Polyethylenglykol = Macrogol

PG Propylenglykol

PHMB Polyhexamethylenbiguanid = Polyhexanid

PVA Polyvinylalkohol

PVP Polyvenylpyrolidon $=$ Povidon

S Schweregrad

TA Trockenes Auge

Tbl Tabletten

TEM Tränenersatzmittel

TM Tränenmeniskus

TTA Therapeutika für das Trockene Auge

u/o und/oder

(-) keine Angaben

\# TEM/TTA, in Österreich nicht direkt erhältlich; Landesangaben in Abb. 3 , Spalte 8

* Mehrere verschiedene Firmen/Hersteller

** Interdisziplinäre Untersuchungen unabhängig vom Schweregrad durchzuführen

\section{Einleitung, Hintergrund}

Die Behandlung des Trockenen Auges stellt immer noch eine Herausforderung für AugenärztInnen dar. Dieses komplexe Krankheitsbild mit subjektiven Beschwerden durch Veränderungen des Tränenfilms und der Augenoberfläche verursacht, wird durch entzündlich-immunologische, hormonelle und toxische Komponenten beeinflusst [1].

Zudem wird die Palette von Tränenersatzmitteln (TEM) und anderer Therapeutika für das Trockene Auge (TTA) zur Beeinflussung dieses Krankheitsbildes immer größer, aber auch unübersichtlicher.

Ziel dieser Arbeit ist es, die Behandelbarkeit zu erleichtern, indem die Komponenten der Benetzungsstörung den therapeutischen Möglichkeiten - unter Berücksichtigung der diagnostischen Gegebenheitengegenübergestellt werden.

\section{Methode}

Diagnostische und therapeutische Vorgaben -entsprechend des Dry Eye Workshop 2007 [2], des Delphi Pa-
Tab. 1 Therapiemöglichkeiten des Trockenen Auges. (Mod. nach DEWS 2007 [2])

\begin{tabular}{|c|c|}
\hline A) Lubrikantien & Tränenersatzmittel (TEM): Gleitmittel \\
\hline & Aw - wässrige Phase - niedrig viskös \\
\hline & Am - muzinös - benetzend, hoch viskös \\
\hline & Al - lipidhältig \\
\hline & Ao - osmoprotektiv \\
\hline & $\begin{array}{l}\text { Ae - Wirkung auf das Epithel: Hyaluronat, Dexpan- } \\
\text { thenol, Vitamin A }\end{array}$ \\
\hline B) Tränenretentic & \\
\hline C) Tränenstimula & \\
\hline D) Biologische TE & rum \\
\hline E) Anti-inflamma & : Steroide, CsA, Tetracycline \\
\hline F) Essentielle Fet & \\
\hline G) Lidrandhygien & \\
\hline H) Schutz vor Un & nflüssen \\
\hline I) Sonstige Mittel & \\
\hline
\end{tabular}

nels 2006 [3] und den Leitlinien für das Trockene Auge der ÖOG 2012 [4] werden zu einem Arbeitsprozess zusammengefasst.

Dabei werden den therapeutischen Möglichkeiten (Tab. 1) diagnostische Parameter zugeordnet und weitere Informationen zur Anwendbarkeit der Therapien beschrieben (Tab. 2, [5]).

Die Einteilung in die Schweregrade des Trockenen Auges sind in der Tab. 3 dargestellt [3].

Der Arbeitsablauf, welcher die Schritte von der Diagnose zur Therapie erleichtern soll, wird aufgrund von wissenschaftlichen, logistischen und empirischen Erkenntnissen erstellt.

In diesem Prozess werden die in Österreich erhältlichen TEM, mit ihren Eigenschaften sowie deren $\mathrm{Zu}$ ordnung zu den Tränenfilm- und Augenoberflächenparametern inkludiert. Die Auswahl der TEM erfolgte, soweit Daten ausreichend vorhanden waren. Es werden aber auch Methoden und Geräte in die Therapieoptionen eingeschlossen.

Die Erstellung dieser Arbeitstabelle soll als Grundlage zur erleichterten Behandlung des Trockenen Auges dienen.

\section{Resultate}

Die Therapieoptionen modifiziert nach dem DEWS Report 2007 (Tab. 1; [2]) ergaben unterschiedliche Therapiekonzepte (A-I) (Tab. 1 und 2), welche in weitere Untergruppen eingeteilt werden konnten (Tab. 2).

Diese Therapiegruppen wurden den diagnostischen Methoden gegenübergestellt (Tab. 2).

Die Zuordnung der diagnostischen Parameter zu den Therapiegruppen erfolgte für:

- Niedervisköse Mittel (Aw) zum wässrigen Phasendefizit.

- Hochvisköse Mittel, Hyaluronsäurepräparate ab $0,19 \%$, abhängig vom Molekulargewicht, sowie Gele (Am) zum muzinösen Phasendefizit. 
Tab. 2 Diagnostik mit Zuordnung zu Therapiegruppen (Mod. nach DEWS 2007)

\begin{tabular}{|c|c|c|}
\hline \multirow[t]{2}{*}{ Diagnostik } & Zuordnung zu Therapiegruppen (Th-Gr) & Abkürzung Th-Gr \\
\hline & Lubrikantien & A \\
\hline Tränenmeniskus verringert, Schirmer Test ohne Lokalanästhesie $\leq 10$ mm & Lubrikantien - wässrige Phase & Aw \\
\hline $\begin{array}{l}\text { Schleimiges Sekret, BUT } \leq 5 \text { sek, Schirmer Test/Tränenmeniskushöhe im } \\
\text { Normbereich oder erhöht, Trockenheit bei Epiphora }\end{array}$ & Lubrikantien - Muzin Phase & $\mathrm{Am}$ \\
\hline $\begin{array}{l}\text { Blepharitis, Meibom-Drüsen-Sekret verändert, pathologische Lipidinterfe- } \\
\text { renz }\end{array}$ & Lubrikantien - Lipide & Al \\
\hline Erhöhte 0smolarität; (>305 m0sm/L) & Lubrikantien - Hypoosmolar, Osmoprotektiva & Ao \\
\hline $\begin{array}{l}\text { Stippung, Erosio, Epitheliopathie } \\
\text { verzögerte Wundheilung der Hornhaut }\end{array}$ & $\begin{array}{l}\text { Wunddheilungsfördernd } \\
\text { Epithel-protektiv }\end{array}$ & $\mathrm{Ae}$ \\
\hline $\begin{array}{l}\text { Mäßig reduzierter Schirmer Test/Tränenmeniskus + sehr starke Sicca-Sym- } \\
\text { ptomatik, rascher Tränenabtransport }\end{array}$ & $\begin{array}{l}\text { Retention der Tränenflüssigkeit } \\
\text { Punctum Plugs }\end{array}$ & B \\
\hline $\begin{array}{l}\text { Verringerte Sekretion (Tränendrüsen, Meibom-Drüsen, Becherzellen); verrin- } \\
\text { gerter Schirmer-Test/Tränen- meniskus, Therapieresistenz herkömmlicher } \\
\text { TEM }\end{array}$ & Stimulation & C \\
\hline $\begin{array}{l}\text { Schwere Sicca-Symptomatik, Erosion, Keratitis, Ulkus, Therapieresistenz, } \\
\text { reduzierte Hornhautsensibilität }\end{array}$ & $\begin{array}{l}\text { Biologische TEM } \\
\text { Serum, Albumin }\end{array}$ & D1 \\
\hline Erosion, Ulkus & Regenerative Agentien: & D2 \\
\hline \multirow{3}{*}{$\begin{array}{l}\text { Entzündungszeichen (Rötung, Sekret, Schmerzen), } \\
\text { Autoimmunerkrankungen, Therapieresistenz; deutliche } \\
\text { Meibom-Drüsen-Dysfunktion, assoziierte Hauterkrankungen }\end{array}$} & $\begin{array}{l}\text { Entzündungshemmung: } \\
\text { Steroide (Kurzfristige Pulstherapie) }\end{array}$ & $\begin{array}{l}\mathrm{E} \\
\mathrm{E} 1\end{array}$ \\
\hline & Cyclosporin A (Dauertherapie) & E2 \\
\hline & Tetracycline; Makrolide & E3 \\
\hline Unspezifische Entzündungszeichen & Zusatzsubstanzen (z. B. Euphrasia, Curcuma) & E4 \\
\hline $\begin{array}{l}\text { Antimikrobiell nachgewiesene Infektionen (Bakterien, Milben), an den Lidern } \\
\text { und an der Bindehaut }\end{array}$ & Antimikrobielle Therapie & E5 \\
\hline Unspezifische Therapieresistenz & $\begin{array}{l}\text { Antioxidantien } \\
\text { auch Kurmittel (Iontophorese) }\end{array}$ & E6 \\
\hline Überreizung, allergische Symptome (Juckreiz, tarsale Follikel) & Antiallergica & E7 \\
\hline $\begin{array}{l}\text { Meibom-Drüsen-Dysfunktion (MGD), therapieresistente Entzündungszeichen } \\
\text { am Lidrand, verstopfte Meibom-Drüsen, verändertes Meibom-Drüsen-Sekret }\end{array}$ & Essentielle Fettsäuren & $\mathrm{F}$ \\
\hline \multirow{2}{*}{$\begin{array}{l}\text { Meibom-Drüsen-Dysfunktion (MGD), therapieresistente Lidrandentzündung, } \\
\text { verstopfte Meibom-Drüsen, verändertes Meibom-Drüsen-Sekret, veränder- } \\
\text { ter Fettfilm, Ablagerung an den Cilien, Dropout in der Meibographie }\end{array}$} & $\begin{array}{l}\text { Physikalische Therapie des Lidrandes } \\
\text { (Wärme, Massage, Reinigung des Lidrandes) }\end{array}$ & G \\
\hline & Schutz vor Umwelteinflüssen & H \\
\hline Empfindlichkeit auf Umwelt-Einflüsse & Schutzbrillen & $\mathrm{H} 1$ \\
\hline \multirow[t]{2}{*}{$\begin{array}{l}\text { Therapieresistenz; Oberflächenproblem, filiforme Keratitis, rezidivierende } \\
\text { Erosio, Ulkus }\end{array}$} & $\begin{array}{l}\text { Verbandlinsen } \\
\text { Sklerallinsen }\end{array}$ & H2 \\
\hline & Sonstige Therapien & I \\
\hline Hyperalgesie, Blinzeltics, inkomplette Lidschläge & $\begin{array}{l}\text { Nervale Therapie } \\
\text { Schmerzmittel }{ }^{\star \star \star \star} \\
\text { Interdisziplinär: Psychiatrie, Neurologie; Blinzelübungen }\end{array}$ & 11 \\
\hline Vegetative Dystonie, allgemeine Nervosität, Unruhe & $\begin{array}{l}\text { Komplementäre Medizin, Akupunktur, Entspan- } \\
\text { nungstechniken }\end{array}$ & 12 \\
\hline $\begin{array}{l}\text { Psychologische Probleme - Störungen } \\
\text { Persönlichkeitsstörungen: Phobien, Depressivität, Zwänge }\end{array}$ & Psychologische Intervention & 13 \\
\hline Hormonell bedingte Erkrankungen in Verbindung mit dem Trockenen Auge & $\begin{array}{l}\text { Hormonelle Therapie } \\
\text { Interdisziplinär: Gynäkologie, Endokrinologie } \\
\text { Lokale Hormontherapie }\end{array}$ & 14 \\
\hline $\begin{array}{l}\text { Operationen } \\
\text { Lidfehlstellung, Conjunctivochalasis; } \\
\text { Ausgeprägter Tränenmangel }\end{array}$ & $\begin{array}{l}\text { Chirurgische Sanierung } \\
\text { Bindehautresektion, Drüsen Transplantation; operativer } \\
\text { Punktum Verschluss }\end{array}$ & 15 \\
\hline $\begin{array}{l}\text { Allgemeinerkrankungen (autoimmun, hormonell, nerval, psychisch) mit } \\
\text { Wirkung auf den Tränenfilm/Augenoberfläche }\end{array}$ & $\begin{array}{l}\text { Interdisziplinäre therapeutische Intervention } \\
\text { (Rheumatologie, Endokrinologie, Neurologie, Psychiatrie) }\end{array}$ & 16 \\
\hline
\end{tabular}


Tab. 3 Schweregrade des Trockenen Auges

\begin{tabular}{|c|c|c|c|c|}
\hline Schweregrad DEWS 2007 & 1 & 2 & 3 & 4 \\
\hline $\begin{array}{l}\text { Beschwerden, Schwere, } \\
\text { Häufigkeit }\end{array}$ & $\begin{array}{l}\text { Leicht } \mathrm{u} / 0 \text { episodisch } \\
\text { unter Umweltbelastung }\end{array}$ & $\begin{array}{l}\text { Mäßig episodisch, } \\
\text { chronisch, } \pm \text { Belastung }\end{array}$ & Schwer, häufig belastend & $\begin{array}{l}\text { Schwer } \mathrm{u} / 0 \text { behindernd ständig } \\
\text { belastend }\end{array}$ \\
\hline Visuelle Symptome & $\begin{array}{l}\text { Keine oder episodisch } \\
\text { leichte Ermüdung }\end{array}$ & $\begin{array}{l}\text { Lästig u/o episodisch } \\
\text { Aktivitätseinschränkung }\end{array}$ & $\begin{array}{l}\text { Lästig, chronisch u/o ständig, } \\
\text { Aktivitätseinschränkung }\end{array}$ & Ständig $\mathrm{u} / \mathrm{o}$ behindernd \\
\hline Bindehautinjektion & Keine bis leicht & Leicht & Mäßig & Stark \\
\hline Bindehautanfärbung & Keine bis leicht & Variabel & Mäßig bis ausgeprägt & Ausgeprägt \\
\hline $\begin{array}{l}\text { Hornhautanfärbung (Dichte/ } \\
\text { Fläche) }\end{array}$ & Keine bis leicht & Variabel & Ausgeprägt zentral & Schwere punktförmige Erosionen \\
\hline Hornhaut/TränenZeichen & Keine bis leicht & $\begin{array}{l}\text { Leichte Partikel, vermin- } \\
\text { derter Tränenmeniskus }\end{array}$ & $\begin{array}{l}\text { Fädchenkeratitis, Schleimver- } \\
\text { klumpung, vermehrt Tränenpar- } \\
\text { tikel }\end{array}$ & $\begin{array}{l}\text { Fädchenkeratitis, Schleimverklum- } \\
\text { pung, vermehrte Tränenpartikel, } \\
\text { Ulzeration }\end{array}$ \\
\hline Lid/MeibomDrüsen & MGD variabel präsent & MGD variabel präsent & Häufig & $\begin{array}{l}\text { Trichiasis, Keratinisierung, Symble- } \\
\text { pharon }\end{array}$ \\
\hline TFBUT (sek) & Variabel & $\leq 10$ & $\leq 5$ & $\leq 2$ \\
\hline Schirmer Test (mm/5 min) & Variabel & $\leq 10$ & $\leq 5$ & $\leq 2$ \\
\hline
\end{tabular}

- Lipidhältige Mittel (Al) zum Lipidphasendefizit.

- Hypoosmolare Mittel zur Kompensation des hyperosmolaren Tränenfilms, Osmoprotektive Mittel (Ao) beinhalten kompatible Solute (Trehalose, Erythrol, Carnithin, Ectoin), welche die Zellen vor den Folgen des hyperosmolaren Tränenfilms schützen [6].

- Epithelprotektion (Ae): Hyaluronsäurepräparate unkonserviert ab 0,15\%, Vitamin-A, Heparin [7, 8], Dexpanthenol $[9,10]$.

- Tränenretention (B): Punctum Plugs [11].

- Stimulantien (C): Mittel mit sekretionsfördernder Wirkung auf die Drüsenzellen [12].

- Biologische TEM (D): körpereigene Substanzen (Serum, Plasma, Albumin) sowie Matrixtherapie bei Ulcera [13].

- Mittel mit antiinflammatorischer Wirkung (E).

- Omega-3-Fettsäuren (F).

- Lidpflege, physikalische Therapie des Lidrandes (G).

- Umweltfaktoren (H), Schutz vor Umwelteinflüssen, Schutzbrillen.

- Verbandlinsen/Sklerallinsen.

- Sonstige Therapeutika (I) durch operative Eingriffe im Zusammenhang mit der Tränenproduktion, systemische Therapien aber auch interdisziplinäre Zusammenarbeit bei systemischen Prozessen mit Einfluss auf die Tränenproduktion: neurologische, endokrinologische, dermatologische, psychologische Erkrankungen, ebenso komplementärmedizinische Methoden.

- Konservierte Präparate sollten wegen ihrer toxischen Wirkung nur kurzfristig und in niedriger Tropffrequenz angewendet werden. Daher wurden diese dem Schweregrad 1 bis maximal 2 zugeordnet, Quartäre Ammoniumverbindungen (BAC, Cetrimid) wurden nur dem Schweregrad 1 zugeordnet [14].

- Für den Schweregrad der Benetzungsstörung wurde die Tabelle aus dem Delphi Report herangezogen (Tab. 3).
In der eigentlichen Arbeitstabelle (Abb. 3) werden nun diese diagnostischen Zuordnungen zu Therapiegruppen den einzelnen Therapeutika zugewiesen, wobei zwischen einer primären Zuordnung und erweiterten Zuordnungen unterschieden wird.

Innerhalb der primären Zuordnung werden die Therapeutika alphabetisch aufgereiht. Zuerst scheint der Handelsname auf, dann die Inhaltsstoffe, die gleichwertig für die Behandlungsgruppe sind.

Für die optimale Therapie ergeben sich folgende Arbeitsschritte:

- Untersuchung/Diagnose (Tab. 2),

- Überlegung der Therapieoptionen (Tab. 1, 2),

- Zuordnung zu den Therapiegruppen (Tab. 2-Spalte "Zuordnung“),

- Zuordnung zum Schweregrad (Tab. 3),

- Auswahl der Therapeutika (Abb. 3): „Zuordnung“ $\rightarrow$ "Name“.

Es werden 149 TEM/TTA in der Abb. 3 genannt. Die Verteilung der TEM ist in der Abb. 1 ersichtlich. In der Abb. 2 ist die Zuordnung der TEM/TTA zum Schweregrad der zu behandelnden Beschwerden dargestellt.

Die Verteilung von TEM und TTA bezogen auf die Hauptwirkung entsprechend der Zuordnung zur Diagnostik zeigt eine Gewichtung nieder- und hochvisköser Mittel, aber auch entzündungshemmender Mittel (Abb. 1).

Die Verteilung der TTA/TEM entsprechend der Zuordnungen zum Schweregrad zeigt eine Häufung für die milderen Formen des Trockenen Auges Grad 1 und 2, wohingegen die Anzahl der TTA/TEM für höhere Schweregrade geringer ist (Abb. 2).

\section{Diskussion}

Die ursprünglich rein empirische Behandlung des Trockenen Auges hat durch zahlreiche Arbeiten tiefer greifende Aspekte gewonnen [15, 16].

Es bleiben aber weiterhin zahlreiche Probleme bestehen, welche therapeutisch nicht ausreichend zu lö- 
Abb. 1 Verteilung der Häufigkeiten bezogen auf die Hauptwirkung und alle Zuordnungen von Tränenersatzmitteln, Pharmazeutika und Methoden entsprechend der Zuordnung zur Diagnostik (Siehe Abb. 3, Spalten 1 und 2)
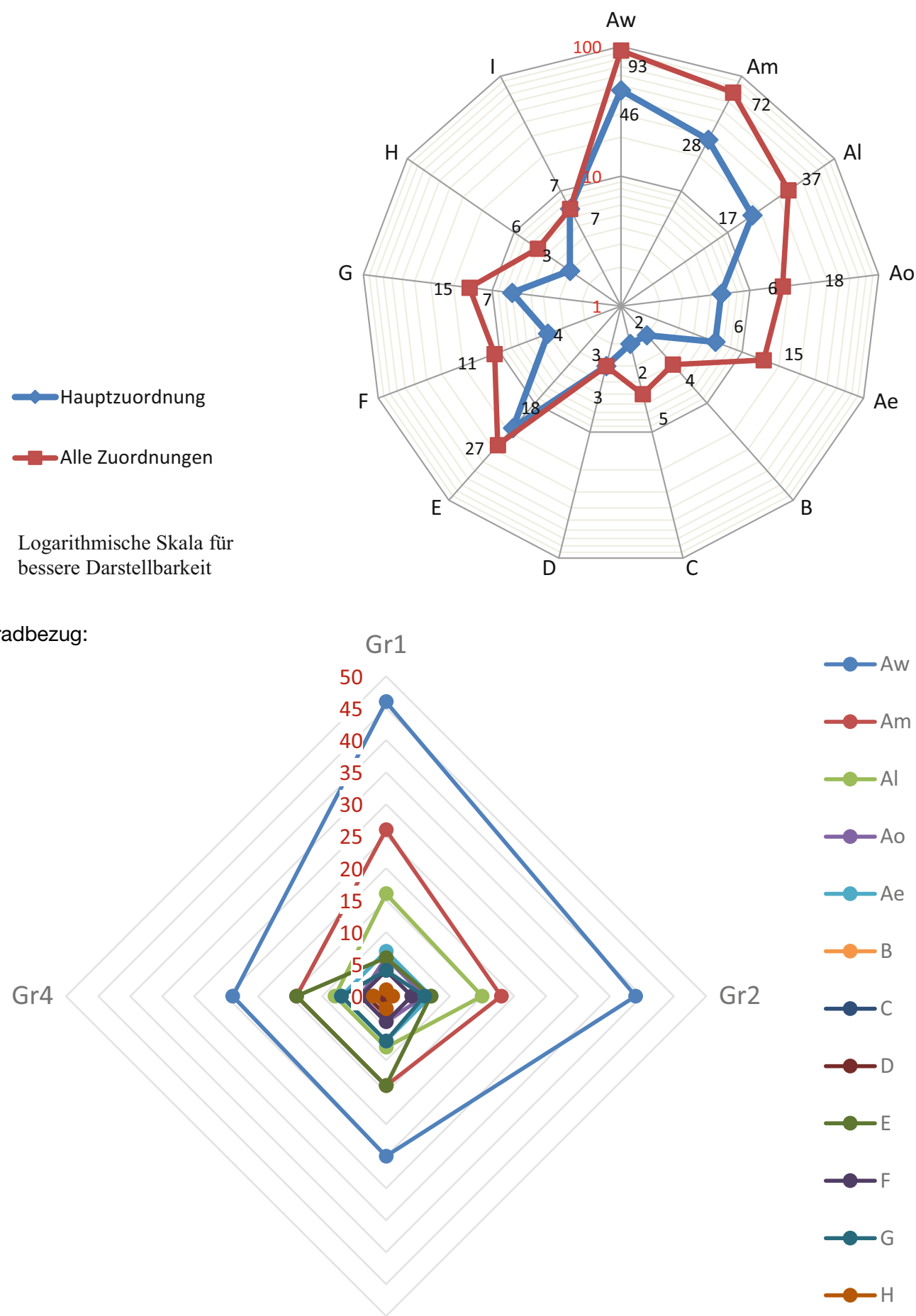

Gr3 sen sind. Dazu gehören die Diskrepanz von subjektiven und objektiven Symptomen beim Trockenen Auge [17], aber auch unterschiedliche Ansichten zur Ätiologie, Pathogenese und zur Therapie dieser Erkrankung sowie zur Bedeutung der verwendeten Substanzen [18].

Die einfachste Behandlung entspricht dem empirischen Ausprobieren von TEM. Dies führt aber zu sehr unklaren Effekten und bedarf daher weiterer Charakterisierungen.

Die Diagnostik der einzelnen Tränenfilm- und Augenoberflächenparameter ist deshalb von Bedeutung, da sie Details der Erkrankung besser erkennen lässt $[5,15]$. Dadurch können die verschiedenen TEM nun aufgrund der Ähnlichkeiten der Inhaltsstoffe den Störungen adäquater zugeordnet werden. 
In der Tab. 2 (Diagnostik) wird eine Liste von $\mathrm{Zu}$ ordnungen getroffen, welche der Erkennung der einzelnen Tränenfilmphasen-Defizite dient. Diese finden sich auch in der Abb. 3 wieder, als Haupt-, und als Nebenzuordnung.

Die TEM wirken zumeist auf mehrere Ebenen, welche in der Abb. 3 in der 2. Spalte ersichtlich sind. Es entspricht aber einer praktischen Vereinfachung, jedem Mittel eine Hauptzuordnung zu geben (Abb. 3, Spalte 1), um entsprechend der Diagnose TEM und TTA zielführender auswählen zu können. Die Ähnlichkeit der Inhaltsstoffe (Abb. 3, Spalte 5) wird für einzelne TEM durch diverse Substanzen, wie Konservierungsmittel, Zusätze (Puffer, Elektrolyte, Emulgatoren etc.), physikalische und pflanzlichen Eigenschaften (Spalte 6-7) verringert.

Die Zuordnung zum Schweregrad (Tab. 3; [3, 19]) entsprechend älteren Versuchen, das Krankheitsbild zu vereinfachen, wird auch in der Arbeitstabelle berücksichtigt. Für den Schweregrad gelten subjektive Beschwerden und objektive Zeichen (Färbetests, Messparameter siehe Tab. 2 und Tab. 3). Der subjektive Schweregrad der Erkrankung hängt zusätzlich auch von zahlreichen negativen psychischen Einflüssen ab, wie der Lebensqualitätsminderung durch das Trockene Auge, Ängsten und Depressionen und ist damit nur bedingt einzelnen TEM/okulären Oberflächentherapien zuzuordnen [20, 21].

Die Zuordnungen der Therapeutika erfolgt nach Literaturangaben, Testberichten, Erfahrungsberichten, Berichten von KollegInnen, eigener Erfahrung und nach Vorgaben durch die Art der Inhaltstoffe. Die Anordnung der TEM/TTA erfolgt entsprechend der Gruppen (A-I), die Produktnamen sind alphabetisch aufgelistet. Die unterschiedlichen Ätiologien werden nicht gesondert dargestellt, da sie im DEWSReport sowie in der „Triple Classification“ ausführlich beschrieben wurden $[1,18]$. Sie werden aber in der Gruppe $\mathrm{H}$ wegen der Notwendigkeit einer interdisziplinären Zusammenarbeit erwähnt.

Inhalt der bisherigen TEM-Listen waren verschiedene Substanzklassen, die aber keinen Bezug zur Dia- gnose des Trockenen Auges hergestellt haben oder den Vorgaben des DEWS 2007 Reports entsprachen $[2,22]$.

Eine bessere Wirksamkeit von gezielten Behandlungen im Vergleich zu zufälliger TEM Auswahl wurden beschrieben [23].

In dieser Aufstellung findet sich eine Darstellung der TEM (Polymer, Osmolarität, Konservierungsmittel) [24], der entzündungshemmenden oder immunmodulatorischen Substanzen [25, 26], der Osmoprotektion [27-29], Hormone [30, 31], Punktum Plugs [32], Omega-3-Fettsäuren [33] und der autologen Serum-Augentropfen [34, 35]. Außerdem wurden alternative Methoden wie Akupunktur [36, 37], und Geräte einbezogen [38, 39], ebenso spezielle Trägersubstanzen[40] und Mittel zur zentralen Anregung der Drüsentätigkeit [41].

Probleme bei der Behandlung bereiten die Schwankungen der Symptome und die Veränderungen des Tränenfilms nach begonnener Behandlung (Rolando M, Vortrag Zürich 2014). Dies bedeutet, daß eine wiederholte Diagnostik mit Therapieanpassung erfolgen muß.

Diese Zusammenstellung wurde nach bestem Wissen durchgeführt, mit zur Zeit aktuellen erhältlichen TEM und Methoden, von welchen ausreichend Informationen vorhanden waren.

Nicht in Österreich erhältliche Präparate werden nur dann erwähnt, wenn sie von besonderer Bedeutung sind. Diese werden in der Arbeitstabelle (Abb. 3) in Spalte 7 mit Landesangabe gekennzeichnet.

\section{Schlussfolgerung}

Diese Arbeit enthält Tabellen, welche die Auswahl von Therapeutika für das Trockene Auge erleichtern soll. Der Arbeitsablauf zur Behandlung des Trockenen Auges zeigt die Schritte von der Symptomatik, Diagnostik und Einordnung der subjektiven und objektiven Parameter bis zur vorgeschlagenen optimierten Therapie. 
Abb. 3 Arbeitstabelle: Gegenüberstellung der in Österreich" ${ }^{\#}$ erhältlichen Therapeutika zur Diagnostik des Trockenen Auges (Aktuell Oktober 2015)

\begin{tabular}{|c|c|c|c|c|c|c|c|}
\hline Spalte 1 & Spalte 2 & Spalte 3 & Spalte 4 & Spalte 5 & Spalte 6 & Spalte 7 & Spalte 8 \\
\hline $\begin{array}{c}\text { Primäre } \\
\text { Zuordnung }\end{array}$ & $\begin{array}{l}\text { Zuord - } \\
\text { nungen }\end{array}$ & $\begin{array}{l}\text { Schwere- } \\
\text { grad }\end{array}$ & Name & Inhalt (Auswahl) & $\begin{array}{c}\text { Konservie- } \\
\text { rungs- } \\
\text { mittel }\end{array}$ & Besonderheit & Firma \\
\hline \multicolumn{8}{|c|}{ Aw -wässrig: Tränenmeniskus verringert, Schirmer $\leq 10 \mathrm{~mm}$} \\
\hline Aw & Aw, Am & S1-2 & $\begin{array}{c}\text { Artelac- } \\
\text { Rebalance }{ }^{\circledR}\end{array}$ & HA $0,15 \%$ & Oxyd & $\begin{array}{l}\text { PEG } 8000, \\
\text { Mineralstoffe, } \\
\text { Vitamin B12 }\end{array}$ & Bausch\& Lomb \\
\hline Aw & \multirow[t]{2}{*}{$A w, A m, A e$} & \multirow[t]{2}{*}{ S1-4 } & $\begin{array}{l}\text { Bepanthen } \\
\text { MDO }{ }^{\circledR}\end{array}$ & \multirow[t]{2}{*}{ HA $0,15 \%$} & \multirow[t]{2}{*}{ MDO sine } & \multirow[t]{2}{*}{ Dexpanthenol } & \multirow{2}{*}{ Bayer } \\
\hline Aw & & & $\begin{array}{c}\text { Bepanthen } \\
\text { EDO }{ }^{\circledR}\end{array}$ & & & & \\
\hline Aw & Aw & S1-2 & $\begin{array}{c}\text { Bilofresh+ } \\
\text { Clean }{ }^{\circledR}\end{array}$ & PVP (-) & $\begin{array}{l}\text { EDTA, } \\
\text { PHMB }\end{array}$ & & Bilosa \\
\hline Aw & $\mathrm{Aw}, \mathrm{Am}$ & S1-2 & $\begin{array}{l}\text { Bilofresh/ } \\
\text { Hyaluron } \AA\end{array}$ & \multirow{2}{*}{ HA $0,15 \%$} & \multirow{2}{*}{$\begin{array}{l}\text { MDO: } \\
\text { PHMB } \\
\text { EDO }\end{array}$} & & \multirow[t]{2}{*}{ Bilosa } \\
\hline Aw & $\mathrm{Aw}, \mathrm{Am}, \mathrm{Ae}$ & S1-4 & $\begin{array}{c}\text { Bilofresh/ } \\
\text { Hyaluron } \mathrm{EDO} \otimes \\
\end{array}$ & & & & \\
\hline Aw & $\mathrm{Aw}, \mathrm{Am}$ & S1-2 & $\begin{array}{c}\text { Blink - } \\
\text { Contacts }{ }^{\circledR} \\
\end{array}$ & \multirow[b]{2}{*}{ HA $0,15 \%$} & \multirow[t]{2}{*}{ OcuPure } & \multirow{2}{*}{$\begin{array}{l}\text { Isoosmolar: } \\
295 \mathrm{mOsm} / \mathrm{L}\end{array}$} & \multirow{2}{*}{$\begin{array}{l}\text { Abbot Medical } \\
\text { Optics }\end{array}$} \\
\hline Aw & $\begin{array}{c}\mathrm{Aw}, \mathrm{Am} \\
\mathrm{Ae}\end{array}$ & S1-4 & $\begin{array}{c}\text { Blink - } \\
\text { Contacts }{ }^{\circledR} \text { EDO }\end{array}$ & & & & \\
\hline Aw & $\mathrm{Aw}$ & S1-2 & Genteal ${ }^{\circledR}$ & HPMC $0.3 \%$ & GenAqua & & Théa \\
\hline Aw & Aw & S1-2 & Genteal HA® & HA $0,1 \%$ & GenAqua & & Théa \\
\hline Aw & $A w, E 4$ & $\mathrm{~S} 1-2$ & $\begin{array}{c}\text { Herbavision }{ }^{\circledR} \\
\text { Augentrost }\end{array}$ & \multirow{2}{*}{$\begin{array}{c}\mathrm{HA} 0,05 \% / \mathrm{HPMC} \\
0,3 \%\end{array}$} & \multirow[t]{2}{*}{ PHMB } & \multirow{2}{*}{ Euphrasia 0,5\% } & \multirow[b]{2}{*}{ Omnivision } \\
\hline Aw & $A w, E 4$ & S1-4 & $\begin{array}{c}\text { Herbavision } \\
\text { Augentrost } \\
\text { EDO }{ }^{\circledR} \\
\end{array}$ & & & & \\
\hline Aw & Aw, E6 & $\mathrm{S} 1-2$ & $\begin{array}{l}\text { Herbavision } \\
\text { Blaubeere } \mathbb{}\end{array}$ & $\begin{array}{c}\mathrm{HA} 0,05 \% \text { / HPMC } \\
0,3 \%\end{array}$ & PHMB & $\begin{array}{l}\text { Blaubeere } \\
\text { (Heidelbeere) }\end{array}$ & Omnivision \\
\hline Aw & $\begin{array}{c}A w, A m, A e \\
E 6\end{array}$ & S1-4 & Hyabak® & HA 0,15\%, & Filter/sine & $\begin{array}{c}\text { Actinoquinol, } \\
\text { Trometamol, } \\
\text { Antioxidativer Zusatz } \\
\end{array}$ & Théa \\
\hline Aw & $\mathrm{Aw}, \mathrm{Ae}$ & S1-4 & Hylo-Care ${ }^{\circledR}$ & HA $0,1 \%$ & Filter/sine & Dexpanthenol & Ursapharm \\
\hline Aw & $\mathrm{Aw}$ & S1-4 & Hylo-Comod $®$ & HA $0,1 \%$ & Filter/sine & & Ursapharm \\
\hline Aw & $A w, E 4$ & $\mathrm{~S} 1-2$ & Hylo-Fresh ${ }^{\circledR}$ & HA 0,03\% & Filter/sine & Euphrasia & Ursapharm \\
\hline Aw & $A w$ & S1-4 & $\begin{array}{c}\text { Hylovision } \mathrm{HD} \otimes \\
/ \text { (sine) }\end{array}$ & \multirow[t]{2}{*}{ HA $0,1 \%$} & \multirow[t]{2}{*}{ sine } & & \multirow[t]{2}{*}{ Omnivision } \\
\hline Aw & Aw & S1-2 & Hylovision $H D{ }^{\circledR}$ & & & & \\
\hline Aw & $\mathrm{Aw}, \mathrm{Am}, \mathrm{Ae}$ & S1-2 & $\begin{array}{c}\text { Hylovision HD } \\
\text { plus } ₫\end{array}$ & HA $0,2 \%$ & PHMB & Allantoin & Omnivision \\
\hline
\end{tabular}


Abb. 3 Fortsetzung

\begin{tabular}{|c|c|c|c|c|c|c|c|}
\hline $\begin{array}{c}\text { Primäre } \\
\text { Zuordnung }\end{array}$ & $\begin{array}{l}\text { Zuord- } \\
\text { nungen }\end{array}$ & $\begin{array}{l}\text { Schwere- } \\
\text { grad }\end{array}$ & Name & Inhalt (Auswahl) & $\begin{array}{c}\text { Konservie- } \\
\text { rungs- } \\
\text { mittel }\end{array}$ & Besonderheit & Firma \\
\hline Aw & $\mathrm{Am}, \mathrm{Aw}$ & S1 & Lacrivision ${ }^{\circledR}$ & HPMC $0,32 \%$ & $\mathrm{BAC}$ & mittelviskös & Omnivision \\
\hline Aw & $\mathrm{Aw}, \mathrm{E} 6$ & S1-2 & $\begin{array}{c}\text { LentoNit } \\
\text { Augentropfen }{ }^{\circledR}\end{array}$ & Istotone Lösung & $\begin{array}{l}\text { CHDG } \\
\text { MDO }\end{array}$ & lodid & Optima Pharma \\
\hline Aw & Aw & S1 & $\begin{array}{l}\text { Oculotect- } \\
\text { Fluid }{ }^{\circledR}\end{array}$ & Polyvidon $5 \%$ & BAC & & Théa \\
\hline Aw & Aw & S1 & Okuzell® & HPMC 0,5\% & BAC & & Pharmaselect \\
\hline Aw & $A w, A m, E 5$ & S1-3 & Olixia care ${ }^{\circledR}$ & HA 0,15\% & $\begin{array}{l}\text { Sine / } \\
\text { Filter }\end{array}$ & Zink & Bausch\& Lomb \\
\hline Aw & $\mathrm{Aw}, \mathrm{Am}, \mathrm{Ae}$ & S1-4 & Olixia pure ${ }^{\circledR}$ & HA $0,15 \%$ & Sine & Edelweiß & Bausch\& Lomb \\
\hline Aw & $A w, G$ & S1-4 & Ophthaxia ${ }^{\circledR}$ & Elektrolyt-Lösung & EDO & Elektrolyte, wash out & Bausch\& Lomb \\
\hline Aw & $\mathbf{A m}, \mathbf{A w}$ & S1 & Panvision ${ }^{\circledR}$ & HPMC $0,3 \%$ & Cetrimid & $\begin{array}{c}\text { Dexpanthenol, } \\
\text { mittelviskös }\end{array}$ & Omnivision \\
\hline Aw & Aw & S1 & Prosicca $\mathbb{R}$ & \multirow{2}{*}{ HPMC $0,5 \%$} & BAC & & \multirow{2}{*}{ Agepha Pharma } \\
\hline Aw & Aw & S1-4 & 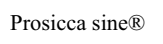 & & Sine EDO & & \\
\hline Aw & Aw & S1 & Protagent $(\mathbb{R}$ & \multirow{2}{*}{ PVP $0,2 \%$} & BAC & & \multirow{2}{*}{ Alcon } \\
\hline Aw & Aw & S1-4 & Protagent sine $(\mathbb{R}$ & & EDO & & \\
\hline Aw & Aw & S1-4 & Safedrop ${ }^{\circledR}$ & HA $0,1 \%$ & Filter/sine & & Omnivision \\
\hline Aw & Aw & S1 & Siccaprotect ${ }^{\circledR}$ & PVA $0,14 \%$ & BAC & Dexpanthenol & UrsaPharm \\
\hline Aw & $A w, A m, E 5$ & S1-4 & Systane EDO $\mathbb{R}$ & $\begin{array}{c}\text { PEG, HP-Guar } \\
(-)\end{array}$ & EDO & Zink-Cl & Alcon \\
\hline Aw & $A w, A m$ & S1-2 & Systane Ultra ${ }^{\circledR}$ & PEG, HP-Guar (-) & Polyquad & & Alcon \\
\hline Aw & $\mathrm{Aw}, \mathrm{Ae}$ & S1-4 & $\begin{array}{c}\text { Tears Again } \\
\text { Augentropfen } \AA\end{array}$ & HA $0,1 \%$ & Filter/sine & Elektrolyte: Mg & Optima Pharma \\
\hline Aw & Aw, E4 & S1 & Vidisan ${ }^{\circledR}$ & \multirow{2}{*}{ PVP 0,2\% } & BAC & \multirow{2}{*}{ Euphrasia } & \multirow{2}{*}{ Bausch\& Lomb } \\
\hline Aw & $\mathrm{Aw}, \mathrm{E} 4$ & S1-4 & 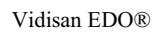 & & EDO & & \\
\hline Aw & Aw & S1 & Viscosan ${ }^{\circledR}$ & HPMC $0,32 \%$ & Cetrimid & $7-13 \mathrm{mPAS}$ & Agepha Pharma \\
\hline Aw & $\mathrm{Aw}, \mathrm{Am}, \mathrm{Ae}$ & S1-4 & $\begin{array}{l}\text { Visiocomfort } \\
\text { EDO } \mathbb{}\end{array}$ & HA 0,15\% & Sine & Dexpanthenol & innomedis/i-med \\
\hline Aw & $A w, A m$ & S1-4 & $\begin{array}{c}\text { Visiocomfort } \\
\text { MDO }{ }^{8}\end{array}$ & HA $0,15 \%$ & MDO sine & & innomedis/ i-med \\
\hline Aw & $\begin{array}{c}\mathrm{Aw}, \mathrm{Am}, \mathrm{Ao}, \\
\mathrm{Ae}\end{array}$ & S1-4 & Vismed EDO ${ }^{\circledR}$ & HA 0,18\%, & EDO sine & $\begin{array}{c}\text { Hyposomolar } 180 \mathrm{~m} \\
\text { Osm/l }\end{array}$ & TRB-Medica \\
\hline Aw & $A w, A o$ & S1-4 & 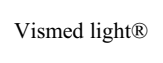 & HA $0,1 \%$ & Filter/sine & $\begin{array}{l}\text { Hypoosmolar } \\
180 \mathrm{~m} \text { Osm/I }\end{array}$ & TRB-Medica \\
\hline
\end{tabular}


Abb. 3 Fortsetzung

\begin{tabular}{|c|c|c|c|c|c|c|c|}
\hline Aw & $\begin{array}{c}\mathrm{Aw}, \mathrm{Am}, \mathrm{Ao}, \\
\mathrm{Ae}\end{array}$ & S1-4 & Vismed multi ${ }^{\circledR}$ & HA $0,18 \%$ & Filter/sine & $\begin{array}{l}\text { Hypoosmolar } \\
180 \mathrm{~m} \text { Osm/I }\end{array}$ & TRB-Medica \\
\hline $\begin{array}{c}\text { Primäre } \\
\text { Zuordnung }\end{array}$ & Zuordnungen & $\begin{array}{l}\text { Schwere- } \\
\text { grad }\end{array}$ & Name & Inhalt (Auswahl) & $\begin{array}{c}\text { Konservier- } \\
\text { ungsmittel }\end{array}$ & Besonderheit & Firma \\
\hline \multicolumn{8}{|c|}{ Am (viskös, Mukcus): positiv für die Muzinschicht, Schleim-Sekret, BUT<5 sek bei normalem Schirmer/Tränenmeniskus } \\
\hline Am & Am & S3-4 & $\begin{array}{l}\text { Acetylzystein- } \\
\text { Solmucol } 5 \% ®\end{array}$ & Acetylzystein & & $\begin{array}{l}\text { Schleimlösung, } \\
\text { Keratitis filiformis }\end{array}$ & $\begin{array}{l}\text { Arzneimittel- } \\
\text { Kompendium der } \\
\text { Schweiz }\end{array}$ \\
\hline Am & Am & S3-4 & $\begin{array}{l}\text { Acetylzystein- } \\
\text { Tirocular } 4 \%{ }^{\circledR}\end{array}$ & Acetylzystein & & $\begin{array}{l}\text { Schleimlösung, } \\
\text { Keratitis filiformis }\end{array}$ & $\begin{array}{c}\text { Riunite Angelini } \\
\text { Franc- } \\
\text { ACRAFSpA } \\
\text { (Rom) } \\
\end{array}$ \\
\hline Am & $A m, A w$ & S1 & Aqua Tears® & Carbomer 0,25\% & BAC & & Théa \\
\hline $\mathrm{Am}$ & $\underset{\text { Ae }}{\text { Am, Aw, }}$ & S1-4 & $\begin{array}{c}\text { Artelac Splash } \\
\text { EDO } \mathbb{}\end{array}$ & \multirow{4}{*}{ HA $0,24 \%$} & keine & \multirow{4}{*}{$\begin{array}{c}\text { Hypoosmolar } \\
170 \mathrm{mOsm} / \mathrm{L}\end{array}$} & Bausch\& Lomb \\
\hline $\mathrm{Am}$ & $\underset{\mathrm{Ae}}{\mathrm{Am}} \mathrm{Aw}$ & S1-4 & $\begin{array}{l}\text { Artelac Splash } \\
\text { MDO } \mathbb{R}\end{array}$ & & $\begin{array}{c}\text { MDO- } \\
\text { Filter-sine }\end{array}$ & & Bausch\& Lomb \\
\hline $\mathrm{Am}$ & $\begin{array}{c}\text { Am, Aw, } \\
\text { Ao }\end{array}$ & S1-2 & $\begin{array}{c}\text { Blink Intensive } \\
\text { Tears } ®\end{array}$ & & OcuPure & & Abbot Medical \\
\hline$A m$ & $\begin{array}{c}\text { Am, Aw, } \\
\text { Ao }\end{array}$ & S1-4 & $\begin{array}{l}\text { Blink Intensive } \\
\text { Tears (EDO) }{ }^{\circledR}\end{array}$ & & EDO & & Optics \\
\hline Am & $\begin{array}{c}\text { Am, Aw, } \\
\text { Ao }\end{array}$ & S1-2 & $\begin{array}{c}\text { Blink Intensive } \\
\text { Tears PLUS } \\
\text { Gel } \AA \\
\end{array}$ & $\begin{array}{c}\text { PEG } 400,0,25 \% \\
\text { HA } 0,38 \%\end{array}$ & OcuPure & $\begin{array}{l}\text { Hypoosmolar } \\
170 \mathrm{mOsm} / \mathrm{L}\end{array}$ & $\begin{array}{l}\text { Abbot Medical } \\
\text { Optics }\end{array}$ \\
\hline $\mathrm{Am}$ & $A m, A w$ & S1-2 & Cellufresh $®$ & CMC $0,5 \%$ & Purite & & Allergan \\
\hline Am & $A m, A w$ & S1-2 & Cellumed $\mathbb{R}$ & CMC $1 \%$ & Purite & & Allergan \\
\hline$A m$ & $\begin{array}{c}\mathrm{Am}, \mathrm{Aw} \\
\mathrm{Ae}\end{array}$ & S1-4 & Comfort Shield ${ }^{\circledR}$ & HA $0,15 \%$ & Filter/sine & $\begin{array}{l}3 \text { Mio Dalton MG, } \\
\text { Hohe Nullscher- } \\
\text { viskosität und niedrige } \\
\text { Viskosität beim } \\
\text { Lidschlag }\end{array}$ & I-com \\
\hline Am & $A m, A w$ & S1-2 & Genteal Gel® & $\begin{array}{l}\text { HPMC 0,30\% } \\
\text { Carbomer }\end{array}$ & GenAqua & & Théa \\
\hline Am & $\begin{array}{c}\mathrm{Am}, \mathrm{Aw} \\
\mathrm{Ae}\end{array}$ & S1-4 & Hylo-Gel $®$ & $\mathrm{HA} 0,2 \%$ & Filter/sine & & Ursapharm \\
\hline Am & $\mathrm{Am}, \mathrm{Ae}$ & S1-2 & Hylovision Gel® & \multirow{2}{*}{ HA 0,3\% } & $\begin{array}{l}\text { EDTA } \\
\text { HMG }\end{array}$ & & \multirow{2}{*}{ Omnivision } \\
\hline Am & $\mathrm{Am}, \mathrm{Ae}$ & S1-4 & $\begin{array}{l}\text { Hylovision Gel } \\
\text { (multi/sine) }{ }^{\circledR}\end{array}$ & & sine & & \\
\hline Am & $\begin{array}{c}\mathrm{Am}, \mathrm{Ae}, \\
\mathrm{Aw}\end{array}$ & S1-4 & $\mathrm{iGel} \mathbb{R}$ & HA 0,2\%, & sine & Trometamol & Agepha Pharma \\
\hline $\mathrm{Am}$ & $\begin{array}{c}\mathrm{Am}, \mathrm{Aw} \\
\mathrm{Ae}\end{array}$ & S1-4 & Ocusan ${ }^{\circledR}$ & HA $0,2 \%$ & EDO & & Agepha \\
\hline $\mathrm{Am}$ & $\begin{array}{c}\text { Am, Aw, } \\
\text { Ae, Ao, E4 }\end{array}$ & S1-4 & Opticum ${ }^{\circledR}$ & HA $0,25 \%$ & EDO & $\begin{array}{c}\text { Euphrasia } 0,1 \% \text {, } \\
\text { Mannitol } 0,1 \%\end{array}$ & Apomedica \\
\hline $\mathrm{Am}$ & $\mathbf{A m}, \mathbf{A w}$ & S1 & Recugel $\circledast$ & Carbomer (-) & Cetrimid & Dexpanthenol & Bausch\&Lomb \\
\hline $\mathrm{Am}$ & $\mathbf{A m}, \mathbf{A w}$ & S1 & Siccaforte $\mathbb{R}$ & Carbomer $0,2 \%$ & Cetrimid & & Agepha Pharma \\
\hline Am & Am & S1 & Siccasan ${ }^{\circledR}$ & Carbomer $0,2 \%$ & Cetrimid & Dexpanthenol 5\% & Agepha Pharma \\
\hline $\mathrm{Am}$ & Am, $\mathbf{E 5}$ & S1-2 & Systane Gel ${ }^{\circledR}$ & PEG, PG, HP-Guar & Polyquad & Zink & Alcon \\
\hline
\end{tabular}




\begin{tabular}{|c|c|c|c|c|c|c|c|}
\hline $\begin{array}{c}\text { Primäre } \\
\text { Zuordnung }\end{array}$ & $\begin{array}{l}\text { Zuord- } \\
\text { nungen }\end{array}$ & $\begin{array}{l}\text { Schwere- } \\
\text { grad }\end{array}$ & Name & Inhalt (Auswahl) & $\begin{array}{c}\text { Konservie- } \\
\text { rungs- } \\
\text { mittel }\end{array}$ & Besonderheit & Firma \\
\hline Am & $\underset{\mathrm{Ae}}{\mathrm{Am}, \mathrm{Aw}}$ & S1-4 & $\begin{array}{c}\text { Tears Again } \\
\text { Gel® }\end{array}$ & HA $0,3 \%$ & Filter/sine & $\begin{array}{c}\text { Elektrolyte: } \mathrm{NaCl} \text {, } \\
\text { NaOHPO4, } \mathrm{Mg} \text {, } \\
\text { NaOHCO3 }\end{array}$ & Optima Pharma \\
\hline $\mathrm{Am}$ & $\mathbf{A m}, \mathbf{A w}$ & S1 & Vidisic $\mathbb{}$ & \multirow{2}{*}{ Carbomer $0,2 \%$} & Cetrimid & \multirow{2}{*}{$\begin{array}{c}\text { (Gel) } 40000-60000 \\
\text { mPAS }\end{array}$} & \multirow{2}{*}{ Bausch\& Lomb } \\
\hline$A m$ & $\mathbf{A m}, \mathbf{A w}$ & S1-4 & Vidisic EDO $®$ & & EDO & & \\
\hline$A m$ & $\mathrm{Am}, \mathrm{Aw}$ & S1 & Viscovision ${ }^{\circledR}$ & Carbomer $0,2 \%$ & Cetrimid & & Omnivision \\
\hline $\mathrm{Am}$ & $\begin{array}{c}\mathrm{Am}, \mathrm{Aw} \\
\mathrm{Ae} \\
\end{array}$ & S1-4 & $\begin{array}{c}\text { Visiocomfort } \\
\text { Gel } \AA\end{array}$ & HA $0,3 \%$ & MDO sine & & Innomedis/ i-med \\
\hline$A m$ & $\begin{array}{c}\text { Am, Aw, } \\
\text { Ao, } \mathrm{Ae} \\
\end{array}$ & S1-4 & $\begin{array}{c}\text { Vismed Gel } \\
\text { EDO } \mathbb{}\end{array}$ & \multirow{2}{*}{ HA $0,3 \%$} & EDO sine & \multirow{2}{*}{$\begin{array}{c}\text { Hypoosmolar } 230 \\
\text { mOsm/l }\end{array}$} & \multirow{2}{*}{ TRB-Medica } \\
\hline $\mathrm{Am}$ & $\begin{array}{l}\text { Am Aw, } \\
\text { Ao, Ae }\end{array}$ & S1-4 & $\begin{array}{l}\text { Vismed Gel } \\
\text { Multi }{ }^{\circledR}\end{array}$ & & Filter/sine & & \\
\hline
\end{tabular}

\begin{tabular}{|c|c|c|c|c|c|c|c|}
\hline $\begin{array}{c}\text { Primäre } \\
\text { Zuordnung }\end{array}$ & $\begin{array}{l}\text { Zuord- } \\
\text { nungen }\end{array}$ & $\begin{array}{l}\text { Schwere- } \\
\text { grad }\end{array}$ & Name & Inhalt (Auswahl) & $\begin{array}{c}\text { Konservie- } \\
\text { rungs- } \\
\text { mittel }\end{array}$ & Besonderheit & Firma \\
\hline \multicolumn{7}{|c|}{ Al-lipidhältig: Blepharitis, Lidrand verklebt, Meibom-Drüsen-Dysfunktion, dünner Fettfilm } & \\
\hline Al & $\mathbf{A l}, \mathbf{A m}$ & S1 & Artelac Lipids ${ }^{\circledR}$ & \multirow{2}{*}{$\begin{array}{l}\text { Carbomer } 2 \mathrm{mg}, \\
\text { Triglyceride }\end{array}$} & Cetrimid & \multirow{2}{*}{ Sorbitol } & \multirow{2}{*}{ Bausch\& Lomb } \\
\hline Al & $\mathbf{A l}, \mathbf{A m}$ & S1-4 & $\begin{array}{c}\text { Artelac Lipids } \\
\text { EDO }{ }^{8}\end{array}$ & & EDO sine & & \\
\hline Al & $\mathbf{A l}, \mathbf{A m}$ & S1 & $\begin{array}{c}\text { Artelac } \\
\text { Nighttime Gel }{ }^{\circledR}\end{array}$ & $\begin{array}{l}\text { Carbomer } 2 \mathrm{mg} \\
\text { Triglyceride }\end{array}$ & Cetrimid & Sorbitol & Bausch\&Lomb \\
\hline $\mathrm{Al}$ & Al & S1-4 & Cationorm $\mathrm{SD} \otimes$ & \multirow{2}{*}{$\begin{array}{c}\text { Paraffinöl, } \\
\text { Glycerol, } \\
\text { Tyloxapol, } \\
\text { Poloxamer 188, } \\
\text { Tris- } \\
\text { Hydrochlorid, } \\
\text { Tromethamin }\end{array}$} & sine & \multirow{2}{*}{$\begin{array}{l}\text { Cetalkonium- } \\
\text { chlorid (als } \\
\text { kationische } \\
\text { Substanz) }\end{array}$} & \multirow{2}{*}{$\begin{array}{l}\text { Santen } \\
\text { BRD }\end{array}$} \\
\hline $\mathrm{Al}$ & Al & S1-4 & $\begin{array}{c}\text { Cationorm MD } \\
\text { sine } \AA\end{array}$ & & Sine & & \\
\hline Al & Al & S2-4 & EvoTears ${ }^{\circledR}$ & $\begin{array}{l}\text { Perfluorhexyl- } \\
\text { octan }\end{array}$ & Sine & $\begin{array}{l}\text { Monosubstanz ohne } \\
\text { Stabilisatoren, } \\
\text { wasserfrei }\end{array}$ & Ursa-Pharm \\
\hline Al & $\mathrm{Al}, \mathrm{Ae}, \mathrm{E} 6$ & S1-2 & Lipomyst ${ }^{\circledR}$ & $\begin{array}{l}\text { Soja-Lecithin, } \\
\mathrm{NaCl}\end{array}$ & Ethanol & $\begin{array}{l}\text { Lipid-Spray } \\
\text { Vitamine A/E }\end{array}$ & $\begin{array}{l}\text { Opticalmax } \\
\text { Medea }\end{array}$ \\
\hline Al & $\mathrm{Al}, \mathrm{Ae}, \mathrm{E} 6$ & S1-2 & LipoNit-Spray ${ }^{\circledR}$ & $\begin{array}{c}\text { Soja-Lecithin, } \\
\text { Liposomen }\end{array}$ & $\begin{array}{c}\text { Phenoxy - } \\
\text { ethanol }\end{array}$ & $\begin{array}{c}\text { Lipid-Spray } \\
\text { Vitamine A/E }\end{array}$ & Optima Pharma \\
\hline Al & $\mathrm{Al}, \mathrm{Ae}, \mathrm{E} 6$ & S1-4 & $\begin{array}{c}\text { LipoNit } \\
\text { Sensitive } \mathbb{}\end{array}$ & Soja-Lecithin & Filter/sine & $\begin{array}{c}\text { Vitamine A/E } \\
\text { Dexpanthenol Lipid- } \\
\text { Spray }\end{array}$ & Optima Pharma \\
\hline Al & Al & S1-4 & $\begin{array}{l}\text { Lipospray } \\
\text { Comfort }{ }^{\circledR}\end{array}$ & $\begin{array}{l}\text { Phospholipid } \\
\text { Hyaluronat (-) }\end{array}$ & Sine & $\begin{array}{l}\text { Lipid-Spray } \\
\qquad(-)\end{array}$ & Innomedis/i-med \\
\hline Al & $\mathrm{Al}, \mathrm{Ae}, \mathrm{E} 6$ & S1-2 & $\begin{array}{l}\text { Omnitears } \\
\text { Spray }{ }^{\circledR}\end{array}$ & $\begin{array}{l}\text { Soja- Lecithin, } \\
\text { Hyaluronat }\end{array}$ & Ethanol & $\begin{array}{l}\text { Dexpanthenol, Vit } \\
\text { A/E, Lipid-spray }\end{array}$ & Omnivision \\
\hline Al & $\mathrm{Al}, \mathrm{Ao}, \mathrm{Am}$ & S1-4 & Optive plus UD® & $\begin{array}{c}\text { CMC } 0,5 \% \\
\text { Rizinusöl }\end{array}$ & EDO & $\begin{array}{c}\text { Erythritol, Glycerol, } \\
\text { L-Carnitin }\end{array}$ & Allergan \\
\hline
\end{tabular}


Abb. 3 Fortsetzung

\begin{tabular}{|c|c|c|c|c|c|c|c|}
\hline $\begin{array}{l}\text { Primäre } \\
\text { Zuordnung }\end{array}$ & Zuordnungen & $\begin{array}{l}\text { Schwere- } \\
\text { grad }\end{array}$ & Name & $\begin{array}{c}\text { Inhalt } \\
\text { (Auswahl) }\end{array}$ & $\begin{array}{c}\text { Konservie- } \\
\text { rungs- } \\
\text { mittel }\end{array}$ & Besonderheit & Firma \\
\hline Al & $\mathrm{Al}, \mathrm{Ao}, \mathrm{Am}$ & S1-2 & Optive plus ${ }^{\circledR}$ & & $\begin{array}{c}\text { MDO- } \\
\text { Purite } \\
\end{array}$ & & \\
\hline Al & $\mathrm{Al}, \mathrm{Ae}, \mathrm{E} 6$ & S1-2 & $\begin{array}{c}\text { Polyeye Comfort } \\
\text { Spray }{ }^{\circledR}\end{array}$ & Soja-Lecithin & $\begin{array}{c}\text { Phenoxy } \\
\text { ethanol }\end{array}$ & $\begin{array}{c}\text { VitA/E } \\
\text { Lipid-Spray }\end{array}$ & Polytech \\
\hline Al & $\mathrm{Al}, \mathrm{Am}$ & S1-2 & $\begin{array}{c}\text { Systane } \\
\text { Balance }{ }^{\circledR}\end{array}$ & $\begin{array}{l}\text { PG, HP-Guar } \\
\text { Paraffinöl, } \\
\text { anionisches } \\
\text { Phospholipid }\end{array}$ & $\begin{array}{c}\text { MDO } \\
\text { Polyquad }\end{array}$ & & Alcon \\
\hline Al & Al, Ae. E6 & S1-4 & $\begin{array}{c}\text { Tears Again } \\
\text { Sensitive Spray }{ }^{\circledR}\end{array}$ & Soja-Lecithin & Sine & $\begin{array}{l}\text { Lipid-Spray } \\
\text { VitA/E } \\
\text { Dexpanthenol }\end{array}$ & Optima Pharma \\
\hline Al & $\mathrm{Al}, \mathrm{Ae}, \mathrm{E} 6$ & S1-2 & $\begin{array}{c}\text { Tears Again } \\
\text { Spray } \AA\end{array}$ & Soja-Lecithin & Ethanol & $\begin{array}{c}\text { VitA/E } \\
\text { Lipid-Spray }\end{array}$ & Optima Pharma \\
\hline $\begin{array}{l}\text { Primäre } \\
\text { Zuordnung }\end{array}$ & Zuordnungen & $\begin{array}{l}\text { Schwere- } \\
\text { grad }\end{array}$ & Name & $\begin{array}{c}\text { Inhalt } \\
\text { (Auswahl) }\end{array}$ & $\begin{array}{l}\text { Konservie- } \\
\text { rungs- } \\
\text { mittel }\end{array}$ & Besonderheit & Firma \\
\hline & o: bei erhöhter & Osmolarität & t Osmoprotektion & & & & \\
\hline Ao & Ao, $\mathrm{Al}, \mathrm{Aw}$ & S1-4 & Hylo-Protect ${ }^{\circledR}$ & $\begin{array}{c}\text { Hyaluronat } \\
0,05 \%\end{array}$ & $\begin{array}{l}\text { Filter/ } \\
\text { sine }\end{array}$ & $\begin{array}{c}\text { Ectoin; (Fett soll } \\
\text { dadurch besser } \\
\text { spreiten) }\end{array}$ & Ursapharm \\
\hline Ao & Ao, $\mathrm{Aw}, \mathrm{Am}$ & S1-2 & Optive ${ }^{\circledR}$ & \multirow[b]{2}{*}{ CMC $0,5 \%$} & $\begin{array}{l}\text { MDO- } \\
\text { Purite }\end{array}$ & \multirow{2}{*}{$\begin{array}{l}\text { Glycerol, } \\
\text { Erythritol, } \\
\text { L-Carnitin }\end{array}$} & \multirow[b]{2}{*}{ Allergan } \\
\hline Ao & Ao, Aw, Am & S1-4 & Optive EDO ${ }^{\circledR}$ & & EDO & & \\
\hline Ao & Ao, Am & S1-2 & Optive Fusion ${ }^{\circledR}$ & $\begin{array}{l}\text { CMC } 0,5 \% \\
\text { HA } 0,1 \%\end{array}$ & $\begin{array}{l}\text { MDO- } \\
\text { Purite }\end{array}$ & $\begin{array}{c}\text { Erythritol, } \\
\text { L-Carnitin, } \\
\text { Glycerol }\end{array}$ & Allergan \\
\hline Ao & $\begin{array}{c}\text { Ao, Am, Aw, } \\
\mathrm{Ae}\end{array}$ & S1-4 & Thealoz Duo ${ }^{\circledR}$ & HA $0,15 \%$, & $\begin{array}{l}\text { Filter/ } \\
\text { sine }\end{array}$ & Trehalose $3 \%$ & Théa \\
\hline Ao & $\mathrm{Ao}, \mathrm{Am}, \mathrm{Ae}$ & S1-4 & $\begin{array}{l}\text { Thealoz Duo } \\
\text { Gel® }\end{array}$ & $\begin{array}{l}\text { Carbomer } 0,25 \% \\
\text { HA } 0,15 \%\end{array}$ & $\begin{array}{l}\text { Filter/ } \\
\text { sine }\end{array}$ & Trehalose 3\% & Théa \\
\hline Spalte 1 & Spalte 2 & Spalte 3 & Spalte 4 & Spalte 5 & Spalte 6 & Spalte 7 & Spalte 8 \\
\hline $\begin{array}{l}\text { Primäre } \\
\text { Zuordnung }\end{array}$ & Zuordnungen & $\begin{array}{l}\text { Schwere- } \\
\text { grad }\end{array}$ & Name & Inhalt (Auswahl) & $\begin{array}{l}\text { Konservier- } \\
\text { ungsmittel }\end{array}$ & Besonderheit & Firma \\
\hline \multicolumn{8}{|c|}{ Ae: Epithel (gut für das Epithel, wundheilungsfördernd): bei Stippung, Erosion, Epitheliopathie } \\
\hline $\mathrm{Ae}$ & $\mathrm{Ae}, \mathrm{Al}$ & S1-4 & $\begin{array}{l}\text { Bepanthen } \\
\text { Augensalbe } \AA\end{array}$ & $\begin{array}{l}\text { Wollwachs, Paraffin; } \\
\text { Vaseline, HDMO }\end{array}$ & sine & $\begin{array}{c}\text { Dexpanthenol } \\
5 \%\end{array}$ & Bayer \\
\hline $\mathrm{Ae}$ & $\mathrm{Ae}, \mathrm{Aw}$ & S1-4 & HyloParin $®$ & HA $0,1 \%$ & $\mathrm{MDO} /$ sine & Heparin-Na [8] & Ursapharm \\
\hline $\mathrm{Ae}$ & Ae, Al, E6 & S1-4 & Oleovital $®$ & $\begin{array}{c}\text { Paraffin, Wollwachs, } \\
\text { Vaseline, } \\
\text { Cetylstearylalkohol }\end{array}$ & Sine & $\begin{array}{c}\text { Vit-A/E, } \\
\text { Dexpanthenol }\end{array}$ & Omnivision \\
\hline $\mathrm{Ae}$ & Ae, $\mathbf{A l}$ & S1-4 & ParinPos Salbe ${ }^{\circledR}$ & $\begin{array}{c}\text { Paraffin, Wollwachs, } \\
\text { Vaseline }\end{array}$ & Sine & Heparin-Na [8] & Ursapharm \\
\hline $\mathrm{Ae}$ & Ae, Al, E6 & S1-4 & VitAPos Salbe ${ }^{\circledR}$ & $\begin{array}{c}\text { Paraffin, Wollwachs, } \\
\text { Vaseline }\end{array}$ & Sine & Vitamin A & Ursapharm \\
\hline
\end{tabular}




\begin{tabular}{|c|c|c|c|c|c|c|c|}
\hline Ae & Ae, Al, E6 & S1-4 & $\begin{array}{c}\text { Vit-A-Vision } \\
\text { Salbe }\end{array}$ & $\begin{array}{c}\text { Paraffin, Wollwachs, } \\
\text { Vaseline, } \\
\text { Cetylstearylalkohol }\end{array}$ & Sine & $\begin{array}{c}\text { Vit-A/E, } \\
\text { Dexpanthenol }\end{array}$ & Omnivision \\
\hline $\begin{array}{c}\text { Primäre } \\
\text { Zuordnung }\end{array}$ & Zuordnungen & $\begin{array}{c}\text { Schwere- } \\
\text { grad }\end{array}$ & Name & Inhalt (Auswahl) & $\begin{array}{c}\text { Konservier- } \\
\text { ungsmittel }\end{array}$ & Besonderheit & Firma \\
\hline B Tränenretention: verringerter Schirmer/Tränenmeniskus, Therapieresistenz & & & keine & $\begin{array}{c}\text { Auflösend nach } \\
\text { einigen Wochen }\end{array}$ & $\begin{array}{c}\text { Oasis } \\
\text { Askin }= \\
\text { Vertrieb }\end{array}$ \\
\hline B & B, Aw & S3-4 & Punktum Plugs* & Ultra-plug ${ }^{\circledR}$ & keine & $\begin{array}{c}\text { Nicht auflösend, } \\
\text { permanent }\end{array}$ & $\mathrm{FCl}$ \\
\hline
\end{tabular}

\begin{tabular}{|c|c|c|c|c|c|c|c|}
\hline \multicolumn{8}{|c|}{ C: Stimulantien: reduzierter Schirmer/TM-Höhe } \\
\hline c & C, Aw & S1-2 & Eloisin $®$ & $\begin{array}{c}\text { Eloisin/Eledoisin } \\
0,04 \%\end{array}$ & $B A C$ & Tränen-stimulation & $\begin{array}{l}\text { Alcon } \\
\text { (Spanien) }\end{array}$ \\
\hline C & C, Aw, Am & S3-4 & Salagen $®$ & Pilocarpin & Tbl & $\begin{array}{c}\text { cave: } \\
\text { Internistische } \\
\text { Freigabe/KI }\end{array}$ & Chiron \\
\hline
\end{tabular}

\begin{tabular}{|c|c|c|c|c|c|c|c|}
\hline $\begin{array}{c}\text { Primäre } \\
\text { Zuordnung }\end{array}$ & Zuordnungen & $\begin{array}{l}\text { Schwere- } \\
\text { grad }\end{array}$ & Name & Inhalt (Auswahl) & $\begin{array}{l}\text { Konservier- } \\
\text { ungsmittel }\end{array}$ & Besonderheit & Firma \\
\hline \multicolumn{8}{|c|}{ D: Biologische TEM: Erosion, Ulkus, Keratitis, Sjögren-Syndrom, GvHD } \\
\hline $\mathrm{D}$ & D1 & S3-4 & $\begin{array}{c}\text { Serum- } \\
\text { Augentropfen } \\
\text { (Autolog, allogen) }\end{array}$ & Serum & sine, EDO & & $\begin{array}{l}\text { Transfusions- } \\
\text { medizinische } \\
\text { Abteilungen }\end{array}$ \\
\hline $\mathrm{D}$ & D1 & S3-4 & $\begin{array}{c}\text { Albumin } \\
\text { Augentropfen }\end{array}$ & Albuminlösung 5\% & Sine & & Apotheke \\
\hline $\mathrm{D}$ & D2 & S3-4 & Cacicol ${ }^{\circledR}$ & $\begin{array}{c}\text { Polycarboxy- } \\
\text { methylglucose-sulfat }\end{array}$ & Sine & Matrixtherapie & Thea \\
\hline
\end{tabular}

\begin{tabular}{|c|c|c|c|c|c|c|c|}
\hline $\begin{array}{c}\text { Primäre } \\
\text { Zuordnung }\end{array}$ & Zuordnungen & $\begin{array}{l}\text { Schwere- } \\
\text { grad }\end{array}$ & Name & Inhalt (Auswahl) & $\begin{array}{l}\text { Konservier- } \\
\text { ungsmittel }\end{array}$ & Besonderheit & Firma \\
\hline \multicolumn{8}{|c|}{ E: Entzündungshemmer: chron. Entzündung, Autoimmunerkrankungen, Therapieresistenz } \\
\hline E1 & E1 & S2-4 & Dexa Edo ${ }^{\circledR}$ & Dexamethason $1 \mathrm{mg}$ & EDO & EDTA & $\begin{array}{l}\text { Bausch\& } \\
\text { Lomb (BRD) }\end{array}$ \\
\hline E1 & E1 & S2-4 & Monodex® & Dexamethason $1 \mathrm{mg}$ & EDO & EDTA & Théa \\
\hline E1 & E1 & S1-2 & $\begin{array}{c}\text { Ultracortenol } \\
\text { Augentropfen }{ }^{\circledR}\end{array}$ & $\begin{array}{l}\text { Prednisolonacetat } \\
\qquad 5 \mathrm{mg}\end{array}$ & BAC & & Agepha \\
\hline E1 & E1 & S2-4 & $\begin{array}{l}\text { Ultracortenol } \\
\text { Salbe } ®\end{array}$ & Prednisolonpivalat & sine & $\begin{array}{c}\text { Wollwachs, weißes } \\
\text { Vaselin, dickflüssiges } \\
\text { Paraffin }\end{array}$ & Agepha \\
\hline E1 & E1 & S1 & Vexol $1 \% ®$ & $\begin{array}{l}\text { Rimexolon } 10 \mathrm{mg} \\
\text { Carbomer }\end{array}$ & BAC & $\begin{array}{c}\text { Polysorbat, EDTA, } \\
\text { Mannitol }\end{array}$ & Alcon \\
\hline E2 & $\mathrm{E} 2, \mathrm{AL}, \mathrm{Am}$ & S3-4 & Cyclosporin & $\begin{array}{l}\text { CsA 0,05-2,0\%, } \\
\text { in Rizinusöl, } \\
\text { Erdnuss, Sesamöl }\end{array}$ & sine & $\begin{array}{c}\text { Schwere Keratitiden, } \\
\text { Hornhaut- } \\
\text { komplikationen }\end{array}$ & $\begin{array}{c}\text { Magistrale } \\
\text { Rezeptur }\end{array}$ \\
\hline
\end{tabular}


Abb. 3 Fortsetzung

\begin{tabular}{|c|c|c|c|c|c|c|c|}
\hline $\begin{array}{c}\text { Primäre } \\
\text { Zuordnung }\end{array}$ & Zuordnungen & $\begin{array}{l}\text { Schwere- } \\
\text { grad }\end{array}$ & Name & Inhalt (Auswahl) & $\begin{array}{c}\text { Konservier- } \\
\text { ungsmittel }\end{array}$ & Besonderheit & Firma \\
\hline E2 & $E 2, A L, A m$ & S3-4 & Ikervis® & $\begin{array}{l}\text { CsA 0,1\%, } \\
\text { Mineralöl }\end{array}$ & Sine & $\begin{array}{c}\text { Kationische Emulsion } \\
\text { bei Keratitis, } \\
\text { Hornhaut- } \\
\text { komplikationen }\end{array}$ & $\begin{array}{c}\text { Santen } \\
\text { (BRD / in } \\
\text { Europa } \\
\text { zugelassen) }\end{array}$ \\
\hline E2 & $\mathrm{E} 2, \mathrm{AL}, \mathrm{Am}$ & S3-4 & Restasis $₫$ & $\begin{array}{l}\text { CsA 0,05\%, } \\
\text { Carbomer, } \\
\text { Rizinusöl }\end{array}$ & sine & $\begin{array}{c}\text { Schwere Keratitiden, } \\
\text { Hornhaut- } \\
\text { komplikationen }\end{array}$ & $\begin{array}{l}\text { Allergan } \\
\text { (in den USA } \\
\text { zugelassen) }\end{array}$ \\
\hline E3 & E3 & S3-4 & Azyter ${ }^{\circledR}$ & $\begin{array}{c}\text { Azithromycin } \\
\text { Augentropfen 1,5\% }\end{array}$ & $\mathrm{EDO} /$ sine & & Théa \\
\hline E3 & E3 & S3-4 & $\begin{array}{c}\text { Doxycyclin } \\
\text { Genericon }{ }^{\circledR} \\
\text { 100mg }\end{array}$ & Doxycyclin & Tbl & $\begin{array}{l}\text { Immunmodulation } \\
\text { Cave KI bei } \\
\text { Schwangeren, } \\
\text { stillenden Müttern, } \\
\text { bei Kindern }\end{array}$ & $\begin{array}{l}\text { Genericon } \\
\text { Pharma } \\
\text { Gesellschaft }\end{array}$ \\
\hline E3 & AL, E3 & S3-4 & $\begin{array}{l}\text { Minostad } \mathbb{R} \\
50 \mathrm{mg}\end{array}$ & Minocyclin & Kps & $\begin{array}{l}\text { Immunmodulation } \\
\text { Cave: KI siehe oben }\end{array}$ & $\begin{array}{c}\text { Stada } \\
\text { Arzneimittel } \\
\text { Wien }\end{array}$ \\
\hline E3 & E3 & S3-4 & Zithromax ${ }^{\circledR}$ & Azithromycin & $\mathrm{Tbl}$ & $\begin{array}{l}\text { Immunmodulation } \\
\text { Macrolid- } \\
\text { antibioticum }\end{array}$ & $\begin{array}{l}\text { Pfizer, } \\
\text { Sandoz }\end{array}$ \\
\hline E4 & $\mathrm{E} 4, \mathrm{G}$ & S1-2 & $\begin{array}{l}\text { Herbavision } \\
\text { Augenbad } \AA\end{array}$ & Hyaluronat (-) & PHMB & $\begin{array}{l}\text { Euphrasia, } \\
\text { Aloe-Vera }\end{array}$ & Omnivision \\
\hline E4 & E4 & S3-4 & NorFlo ${ }^{\circledR}$ & $\begin{array}{l}\text { Curcuma, } \\
\text { CMC }\end{array}$ & Tbl & $\begin{array}{l}\text { Entzündungs- } \\
\text { hemmung }\end{array}$ & $\begin{array}{l}\text { Med-lab/ } \\
\text { Askin }\end{array}$ \\
\hline E4 & $\mathbf{E} 4, \mathbf{G}, \mathbf{A l}$ & S2-4 & Ghee ${ }^{\circledR}$ & Butterschmalz & & Augenbad & $\begin{array}{l}\text { Regenbogen- } \\
\text { apotheke; } \\
\text { Graz }\end{array}$ \\
\hline E5 & E5 & S3-4 & Stromectol $\circledast$ & $\begin{array}{c}\text { Ivermectin } \\
\text { Antihelminticum }\end{array}$ & Tbl & Ad Dermatologie! & Merck \\
\hline E5: & E5 & S $1-4$ & $\begin{array}{l}\text { Teebaumöl 5\%, } \\
\text { Paraffin }\end{array}$ & & sine & $\begin{array}{l}\text { Lidkanten-reinigung } \\
\text { bei Demodex } \\
\text { positiver Blepharitis }\end{array}$ & $\begin{array}{l}\text { Magistrale } \\
\text { Rezeptur }\end{array}$ \\
\hline E7 & E7 & S1-4 & 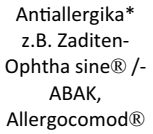 & $\begin{array}{l}\text { Kurzfristig topische } \\
\text { Antiallergica }\end{array}$ & sine & Allergologie & $\begin{array}{l}\text { Thea, } \\
\text { Ursapharm } \\
\text { und andere } \\
\text { Firmen }\end{array}$ \\
\hline
\end{tabular}

\begin{tabular}{|c|c|c|c|c|c|c|c|}
\hline $\begin{array}{c}\text { Primäre } \\
\text { Zuordnung }\end{array}$ & Zuordnungen & $\begin{array}{l}\text { Schwere- } \\
\text { grad }\end{array}$ & Name & Inhalt (Auswahl) & $\begin{array}{l}\text { Konservier- } \\
\text { ungsmittel }\end{array}$ & Besonderheit & Firma \\
\hline \multicolumn{8}{|c|}{ F essentielle Fettsäuren, allg. Prophylaxe (Auswahl)* } \\
\hline $\mathrm{F}$ & $\begin{array}{c}\mathrm{F}, \mathrm{Ae}, \mathrm{Ao}, \mathrm{AL} \\
\mathrm{E6}\end{array}$ & S1-4 & $\begin{array}{c}\text { Remogen } \\
\text { Augentropfen } ®\end{array}$ & $\begin{array}{c}\text { Omega-3 Fettsäuren, } \\
\text { Carbopol980 }\end{array}$ & EDO sine & $\begin{array}{c}\text { Vit. E, Glycerol, } \\
\text { Hydrogel, hypoton } \\
\text { CAVE: Lagerung bei } 4-8^{\circ} \mathrm{C}\end{array}$ & TRB-Medica \\
\hline $\mathrm{F}$ & F, E6 & S1-4 & Hyabak Caps ${ }^{\circledR}$ & $\begin{array}{c}2 \text { Kapseln: Fischöl } \\
560 \text { mg,(davon } 70 \% \\
\text { DHA); Borretschöl } \\
420 \text { mg; (davon } 22 \% \\
\text { GLA) }\end{array}$ & Kps & $\begin{array}{c}\text { Nahrungs-ergänzung: } \\
\text { Vit C,E,B6, B9, B12, } \\
\text { Zink }\end{array}$ & Théa \\
\hline $\mathrm{F}$ & F, E6 & S1-4 & $\begin{array}{l}\text { Ocuvite } \\
\text { Trockenes } \\
\text { Auge }{ }^{\circledR}\end{array}$ & $\begin{array}{c}3 \text { Kapseln: Fischöl } \\
\text { (EPA } 413 \text { mg, DHA } \\
270 \mathrm{mg} \text { ) Borretschöl } \\
\text { (GLA } 15 \mathrm{mg} \text { ) }\end{array}$ & & $\begin{array}{l}\text { Vitamine, } \\
\text { Lutein, } \\
\text { Zeaxanthin, } \\
\text { Mannit }\end{array}$ & $\begin{array}{c}\text { Bausch \& } \\
\text { Lomb }\end{array}$ \\
\hline $\mathrm{F}$ & F, E6 & S1-4 & $\begin{array}{l}\text { Vitalux plus }{ }^{\circledR} \\
\quad \text { Kps) }\end{array}$ & $\begin{array}{l}1 \text { Kapsel: Fischöl } \\
\text { (DHA } 100 \mathrm{mg} \text {, } \\
\text { EPA } 30 \mathrm{mg} \text { ) }\end{array}$ & Kps & $\begin{array}{l}\text { Vitamin C/E, } \\
\quad \text { Lutein, } \\
\text { Zeaxanthin, } \\
\text { Zink, Kupfer }\end{array}$ & Novartis \\
\hline
\end{tabular}




\begin{tabular}{|c|c|c|c|c|c|c|c|}
\hline $\begin{array}{c}\text { Primäre } \\
\text { Zuordnung }\end{array}$ & Zuordnungen & $\begin{array}{l}\text { Schwere- } \\
\text { grad }\end{array}$ & Name & Inhalt (Auswahl) & $\begin{array}{l}\text { Konservie- } \\
\text { rungsmittel }\end{array}$ & Besonderheit & Firma \\
\hline \multicolumn{8}{|c|}{ G Physikalische Therapie des Lidrandes (Wärme, Massage, Reinigung des Lidrandes): MGD, Blepharitis } \\
\hline G & G, C, Al & S1-4 & $\begin{array}{l}\text { Blephacura } \\
\text { Gelmaske }{ }^{\circledR}\end{array}$ & & & $\begin{array}{l}\text { Kalt/Wärme- } \\
\text { Anwendung für die } \\
\text { Lider }\end{array}$ & $\begin{array}{l}\text { Optima } \\
\text { Pharma }\end{array}$ \\
\hline G & G, E6 & S1-4 & $\begin{array}{c}\text { Blephacura } \\
\text { Reinigungsgel } \mathbb{}\end{array}$ & Soja-Lecithin & Ethanol & $\begin{array}{l}\text { Vit A/E, keine } \\
\text { Tenside }\end{array}$ & $\begin{array}{l}\text { Optima } \\
\text { Pharma }\end{array}$ \\
\hline G & G & S1-4 & Blephagel duo ${ }^{\circledR}$ & $\begin{array}{c}\text { Carbomer, } \\
\text { Poloxamer 188, } \\
\text { PEG-90 }\end{array}$ & Sine & Lidpflege & Théa \\
\hline G & G & S1-4 & Blephasol ${ }^{\circledR}$ & \begin{tabular}{|c|} 
Aqua, Polysorbat20, \\
Poloxamer184, PEG-8
\end{tabular} & Sine & Lidpflege & Théa \\
\hline G & G, Al & S1-4 & $\begin{array}{l}\text { Lidranderwär- } \\
\text { mung/ -massage }\end{array}$ & $\begin{array}{l}\text { Diverse Methoden: } \\
\text { z.B.heiße Kompressen }\end{array}$ & - & & - \\
\hline G & $\mathrm{G}, \mathrm{Al}, \mathrm{C}$ & S2-4 & Blephasteam $\mathbb{}$ & Gerät & & $\begin{array}{l}\text { Feuchtigkeit/ } \\
\text { Wärme-brille }\end{array}$ & Théa \\
\hline G & G, C, Al, & S2-4 & Lipiflow ${ }^{\circledR}$ & Gerät & & $\begin{array}{l}\text { Erwärmung und } \\
\text { Massage }\end{array}$ & TearScience \\
\hline \multicolumn{8}{|c|}{ H-Schutz vor externen.Faktoren,Umwelteinfluss-Prophylaxe } \\
\hline $\mathrm{H} 1$ & H & S1-2 & $\begin{array}{c}\text { Hylovision } \\
\text { Augenbad } ®\end{array}$ & $0,9 \% \mathrm{NaCL}, \mathrm{HA}(-)$ & PHMB & Augenbad & Omnivision \\
\hline $\mathrm{H} 1$ & $\mathrm{H} 1, \mathrm{Al}, \mathrm{B}$ & S3-4 & $\begin{array}{c}\text { Schutzbrillen/ } \\
\text {-schalen* }\end{array}$ & & & Oberflächenschutz & div. Firmen* \\
\hline $\mathrm{H} 2$ & $\mathrm{H} 2, \mathrm{~B}$ & S3-4 & $\begin{array}{l}\text { Verbandlinsen / } \\
\text { Sklerallinsen* }\end{array}$ & & - & $\begin{array}{c}\text { Keratitis filiformis, } \\
\text { Hornhaut- } \\
\text { komplikationen } \\
\text { KI: extremer } \\
\text { Tränenmangel }\end{array}$ & $\begin{array}{c}\operatorname{div} \\
\text { Hersteller* }\end{array}$ \\
\hline
\end{tabular}

\begin{tabular}{|c|c|c|c|c|c|c|c|}
\hline $\begin{array}{r}\text { Primäre } \\
\text { Zuordnung }\end{array}$ & Zuordnungen & $\begin{array}{l}\text { Schwere- } \\
\text { grad }\end{array}$ & Name & Inhalt (Auswahl) & $\begin{array}{l}\text { Konservie- } \\
\text { rungsmittel }\end{array}$ & Besonderheit & Firma \\
\hline \multicolumn{8}{|c|}{ I sonstige Mittel und Methoden } \\
\hline 11 & Neurologie & $* *$ & $\begin{array}{c}\text { Hyperalgesie/ } \\
\text { Sensibilitäts- } \\
\text { störungen, } \\
\text { Blinzeltics, } \\
\text { Inkomplette } \\
\text { Lidschläge }\end{array}$ & & & $\begin{array}{l}\text { Blinzelübungen, } \\
\text { Entspannungs- } \\
\text { übungen }\end{array}$ & \\
\hline 12 & $\begin{array}{l}\text { Vegetative } \\
\text { Dystonie }\end{array}$ & $* *$ & $\begin{array}{l}\text { allg. Nervosität, } \\
\text { Unruhe }\end{array}$ & $\begin{array}{l}\text { Autog. Training, } \\
\text { Akupunktur }\end{array}$ & & & \\
\hline 13 & Psychologie & $* *$ & $\begin{array}{l}\text { Psychologische } \\
\text { Probleme - }\end{array}$ & $\begin{array}{l}\text { Psychologische } \\
\text { Intervention }\end{array}$ & & $\begin{array}{c}\text { Persönlichkeits- } \\
\text { störungen: Phobien, } \\
\text { Depressivität, } \\
\text { Zwänge }\end{array}$ & \\
\hline 14 & Endokrinologie & $* *$ & Hormontherapie & $\begin{array}{c}\text { Hormonelle } \\
\text { Erkrankungen } \\
+ \text { +Trockenes Auge }\end{array}$ & & $\begin{array}{l}\text { Interdisziplinär: } \\
\text { Gynäkologie, } \\
\text { Endokrinologie }\end{array}$ & $:$ \\
\hline 14 & Endokrinologie & S3-4 & $\begin{array}{c}\text { Lokale } \\
\text { Hormonsalbe }\end{array}$ & $\begin{array}{l}\text { Östrogen Merk 0,004\%, } \\
\text { Augensalben-grundlage } \\
5 \mathrm{~g}\end{array}$ & sine & $\begin{array}{l}\text { Interdisziplinär: } \\
\text { Gynäkologie }\end{array}$ & $\begin{array}{l}\text { Magistrale } \\
\text { Rezeptur }\end{array}$ \\
\hline 15 & $\begin{array}{c}\text { OP } \\
\text { Indikationen }\end{array}$ & $* *$ & OP & Siehe Tabelle 2 & & & \\
\hline 16 & \begin{tabular}{|c|} 
Systemische \\
Krankheiten \\
mit Bezug zum \\
Tränensystem
\end{tabular} & $* *$ & & $\begin{array}{c}\text { Sonstige Interdisziplinäre } \\
\text { Zusammenarbeit } \\
\text { (Dermatologie, } \\
\text { Rheumatologie,...) }\end{array}$ & & & \\
\hline
\end{tabular}

- *Mehrere verschiedene Firmen/Hersteller /

- **Interdisziplinäre Untersuchungen unabhängig vom Schweregrad durchzuführen

- $\quad$ "Ausnahmen: Landesangabe in Spalte 8

\section{Einhaltung ethischer Richtlinien}

Interessenkonflikt J. Nepp, J. Horwath-Winter, C. Mitsch, I. Boldin, D.F. Rabensteiner und A. Wedrich geben an, dass kein Interessenkonflikt besteht. Die Zusammenstellung von Therapeutika und deren Gegenüberstellung zur Diagnose des Trockenen Auges wurde unabhängig von Firmen erstellt.

Ethische Standards Diese Arbeit beinhaltet keine Studien am Menschen und entspricht den ethischen Richtlinien nach der Deklaration von Helsinki (1964).

Open Access This article is distributed under the terms of the Creative Commons Attribution 4.0 International License (http://creativecommons.org/licenses/by/4.0/), which per- mits unrestricted use, distribution, and reproduction in any medium, provided you give appropriate credit to the original author(s) and the source, provide a link to the Creative Commons license, and indicate if changes were made.

\section{Literatur}

1. [No authors listed]. The definition and classification of dry eye disease: report of the Definition and Classification Subcommittee of the International Dry Eye WorkShop (2007. Ocul Surf. 2007;5(2):75-92.

2. [No authors listed]. Management and therapy of Dry Eye Disease: Report of the Management and Therapy 
Subcommittee of the International DryEyeWorkShop. Ocul Surf. 2007;5(2):163-78

3. Dysfunctional Tear Syndrome Study Group, Behrens A, Doyle JJ, Stern L, et al. Dysfunctional tear syndrome: aDelphiapproach to treatmentrecommendations. Cornea. 2006;25:900-7.

4. Emesz M, Ettl A, Horwath-Winter J, et al. Leitlinien der Kommission für Okuloplastik (Orbita + Dakryologie) der ÖOG. Spektrum Augenheilkd. 2013;27:204-15.

5. Marquart R, Lemp MA. (Hrsg.) Das Trockene Auge in Klinik und Praxis. Berlin: Springer; 1991.

6. Lynch AL, Slaater NK. Mediated trehalose un-loading for reduced erythrocyte osmoticfragilityand phosphatidylserine translocation. Cryo Letters. 2011;32(5):415-24.

7. Kruse FE, Tseng SC. Retinoic acid regulates clonal growth and differentiation of cultured limbal and peripheral corneal epithelium. Invest Ophthalmol Vis Sci. 1994;35(5):2405-20.

8. Aronson SB, ElliottJH, Moore TEJr.. Pathogenetic approach to therapy of peripheral corneal inflammatory disease. Am J Ophthalmol. 1970;70:65-90.

9. Hahne M, Reichl S. Simulation of corneal epithelial injuries by mechanical and corrosive damage: Influence of fetal bovine serum and dexpanthenol on epithelial regeneration in a cell culture model. Ophthalmologe. 2010;107(6):529-36.

10. Dexpanthenol. www.pharmawiki.ch/wiki/index.php? wiki=Dexpanthenol.Zugegriffen: 1. Februar 2016

11. Tai MC, Cosar CB, Cohen EJ, et al. The clinical efficacy of silicone punctal plug therapy. Cornea. 2002;21(2):135-9.

12. Göbbels M, Selbach J, Spitznas M. Effect of eledoisin on tear volume and tear flow in humans as assessed by fluorophotometry. Graefes Arch Clin Exp Ophthalmol. 1991;229(6):549-52.

13. Aifa A, Gueudry J, Portmann A, et al. Topical treatment with a new matrix therapy agent (RGTA) for the treatment of corneal neurotrophic ulcers. Invest Ophthalmol Vis Sci. 2012;53(13):8181-5.

14. Martone G, Frezzotti P, Tosi GM, et al. An in vivo confocal microscopy analysis of effects of topical antiglaucoma therapy with preservative on corneal innervation and morphology. Am J Ophthalmol. 2009;147(4):725-35.

15. Lemp MA. Pathogenesis and classification of dry eye disease. In: Asbell PA, Lemp MA (Hrsg.). Dry eye disease. NewYork: Thieme;2006. S. 16-23.

16. Benitez-del-Castillo JM, Lemp MA. (Hrsg.) Ocular surface disorder. NewDelhi: Medical; 2013.

17. Schmidl D, Witkowska KJ, Kaya S, et al. The association between subjective and objective parameters for the assessment of dry-eye syndrome. Invest Ophthalmol Vis Sci. 2015;56(3):1467-72.

18. Murube J, Nemeth J, Hoh H, et al. The triple classification of dry eye for practical clinical use. Eur J Ophthalmol. 2005;15(6):660-7.

19. Baudouin C, Aragona P, Van Setten G, ODISSEY European Consensus Group members. Diagnosing the severity of dry eye: a clear and practical algorithm. Br J Ophthalm. 2014;98(9):1168-76.

20. Vaart R van der, Weaver MA, Lefebvre C, et al. The association between dry eye disease and depression and anxietyinalarge population-based study. AmJOphthalmol. 2015;159(3):470-4.

21. Erb C, Horn A, Gunthner A, et al. Psychosomatic aspects of patients with primary keratoconjunctivitis sicca. Klin Monatsbl Augenheilkd. 1996;208(2):96-9, German.
22. Kremminger E, Ruckhofer J. (Hrsg.) Salzburger Ophthalmika-Liste. Basel: Novartis; 2003

23. Utheim O, S. Ræder, T.P. Utheim, J.R. et al. Efficacy of dry eye disease treatment based on the 2007 report of the International Dry Eye Workshop (DEWS). EVER 2015 Poster T086.

24. Nepp J, Schauersberger J, Schild G, et al. The clinical use of viscoelastic artificial tears and sodium chloride in dry-eye syndrome. Biomaterials. 2001;22(24):3305-10.

25. Foulks GN, Forstot SL, Donshik PC, et al. Clinical guidelines for management ofDryEyeassociated with SjögrenDisease. OculSurf. 2015;13(2):118-32.

26. Pflugfelder SC. Anti-inflammatory therapy of dry eye. Ocul Surf. 2003;1(1):31-6.

27. Suzuki M, Massingale ML, Ye F, et al. Tear Osmolarity as a Biomarker for Dry Eye Disease severity. Invest Ophthalmol Vis Sci. 2010;51:4557-61.

28. Gilbard JP, Farris RL. Tear osmolarity and ocular surface disease in keratoconjunctivitis sicca. Arch Ophthalmol. 1979;97(9):1642-6.

29. Chen W, Zhang X, Liu M, et al. Trehalose protects against ocular surface disorders in experimental murine dry eye through suppression of apoptosis. Exp Eye Res. 2009;89(3):311-8.

30. Akramian J, Wedrich A, Nepp J, et al. Estrogen therapy in keratoconjunctivitis sicca. Ad Exp Med Biol. 1998;438:1005-9.

31. Fuchsjager-Mayrl G, Nepp J, Schneeberger C, et al. Identification of estrogen and progesterone receptor mRNA expression in the conjunctiva of premenopausal women. Invest Ophthal Vis Sci. 2002;43(9):2841-4.

32. Murube J, Murube E. Treatment of dry eye by blocking the lacrimal canaliculi. Surv Ophthalmol. 1996;40(6):463-80.

33. Hom MM, Asbell P, Barry B. Omegas and Dry Eye: More Knowledge, More Questions. Optom Vis Sci. 2015;92(9):948-56.

34. Celebi AR, Ulusoy C, Mirza GE. The efficacy of autologous serum eye drops for severe dry eye syndrome: a randomized double-blind crossover study. Graefes Arch Clin Exp Ophthalmol.2014;252(4):619-26.

35. Versura P, Profazio V, Buzzi M, et al. Efficacy of standardized and quality-controlled cord blood erum eye drop therapy in the healing of severe corneal epithelial damage in dry eye. Cornea. 2013;32(4):412-8.

36. Nepp J, Derbolav A, Haslinger-Akramian J, et al. Effect of acupuncture in keratoconjunctivitis sicca. Klin Monbl Augenheilkd. 1999;215(4):228-32, German.

37. Nepp J, Wedrich A, Akramian J, et al. Dry eye treatment with acupuncture. A prospective, randomized, double-masked study. Adv Exp Med Biol. 1998;438:1011-6.

38. Benitez Del Castillo JM, Kaercher T, Mansour K, et al. Evaluation of the efficacy, safety, and acceptability of an eyelid warming device for the treatment of meibomian gland dysfunction. Clin Ophthalmol. 2014;8:2019-27.

39. Finis D, Hayajneh J, Konig C, et al. Evaluation of an automated thermodynamic treatment (Lipiflow) systemfor meibomian gland dysfunction: A prospective, randomized, observer-masked trial. Ocul Surf. 2014;12(2):146-54.

40. Macrogol 4000. http://www.pharmawiki.ch/wiki/index. php?wiki=Macrogol\%204000. Zugegriffen: 11. Februar 2016

41. Aragona P, Pietro R Di, Spinella R, et al. Conjunctival epithelium improvement after systemic pilocarpine in patients with Sjogren's syndrome. Br J Ophthalmol. 2006;90(2):166-70. 